\title{
BAUMANN, Anette, Gedruckte Relationen und Voten des Reichskammergerichts vom 16. bis 18. Jahrhundert. Ein Findbuch
}

\section{Christophe Duhamelle}

\section{OpenEdition}

\section{Journals}

Édition électronique

URL : http://journals.openedition.org/ifha/806

DOI : $10.4000 /$ ifha.806

ISSN : 2198-8943

Éditeur

IFRA - Institut franco-allemand (sciences historiques et sociales)

Référence électronique

Christophe Duhamelle, "BAUMANN, Anette, Gedruckte Relationen und Voten des Reichskammergerichts vom 16. bis 18. Jahrhundert. Ein Findbuch », Revue de l'IFHA [En ligne], Date de recension, mis en ligne le 01 janvier 2005, consulté le 22 septembre 2020. URL : http://journals.openedition.org/ifha/806 ; DOI : https://doi.org/10.4000/ifha.806

Ce document a été généré automatiquement le 22 septembre 2020.

(CIFHA 


\title{
BAUMANN, Anette, Gedruckte Relationen und Voten des Reichskammergerichts vom 16. bis 18. Jahrhundert. Ein Findbuch
}

\author{
Christophe Duhamelle
}

1 C'est à un type particulier de documents (la Relatio et le Votum) qu'A.B. consacre ce répertoire, et non à l'ensemble des procès au Tribunal de la Chambre Impériale (Reichskammergericht), un des deux tribunaux d'Empire nés de la Réforme de 1495 et piliers des institutions impériales. Les archives de ces tribunaux, comportant les pièces et les argumentations liées à des milliers de procès, ont été réparties après la fin du Saint-Empire dans de multiples dépôts et sont de mieux en mieux inventoriées ; c'est sur elles que repose en partie le renouvellement remarquable, depuis trois décennies, des études sur l'Empire.

2 À la Chambre Impériale, où la décision était collégiale et le recours à l'écrit systématique, le rapporteur d'un procès résumait très précisément l'affaire, ses pièces, les arguments juridiques (c'était la Relatio) puis proposait une décision par un Votum, le plus souvent suivi par les assesseurs. Ces deux textes étaient archivés à part ; pour l'époque où le tribunal siègeait à Spire (jusqu'à la guerre de la Ligue d'Augsbourg), il n'en reste plus rien, et pour le XVIIIe s. (la Cour est alors à Wetzlar), pas grand-chose.

3 Il fallait donc rechercher ces textes dans les recueils imprimés qui se sont multipliés au début, puis dans la seconde moitié du XVIIe s. surtout. La tâche était complexe, car la plupart donnent un résumé des affaires, et non la reproduction littérale des relations et des votes. On est redevable à A.B. d'avoir présenté (sous une forme analytique un peu rébarbative) 1346 procès au sujet desquels ces textes ont été en partie édités et dont près de $85 \%$ sont antérieurs à 1606 , ainsi que d'avoir, dans la mesure du possible, indiqué le répertoire imprimé renvoyant aux actes archivés de ces procès.

4 La volonté de combler avant tout la lacune du temps de Spire explique peut-être qu'A.B. ait négligé quelques imprimés de la fin du XVIIIe s. où elle aurait trouvé de quoi 
compléter son recueil - on pense à l'abondante production de Johann Jacob Moser ou encore aux 25 volumes de Johann Mader intitulés Sammlung reichsgerichtlicher Erkenntnisse in reichsritterschaftlichen Angelegenheiten (1776-1790). Tel quel (et assorti d'un CD-Rom peu convivial), l'ensemble rendra cependant des services à qui (spécialement les historiens du droit) voudra approfondir la connaissance des procédures et de la culture juridique d'un tribunal qui a joué un rôle déterminant pour l'évolution du droit et pour la formation des élites administratives dans l'Allemagne de l'époque moderne.

5 Christophe DUHAMELLE (MHFA) 